\title{
Las palerías del valle del río Záncara en las postrimerías de la Pequeña Edad del Hielo: Prácticas de control ante la proliferación de áreas pantanosas insalubres en el Centro Peninsular ${ }^{1}$ \\ Palerias in the last centuries of the Little Ice Age in the Záncara river valley: Control practices used to combat the proliferation of unhealthy wetlands in the center of the Iberian peninsular
}

\author{
Isabel Prieto Jiménez*, Concepción Fidalgo Hijano ${ }^{* *}$ y \\ Juan Antonio González Martín ***
}

\section{INTRODUCCIÓN}

La Pequeña Edad del Hielo (P.E.H.), última crisis climática del Holoceno Terminal, alcanzó rango global al afectar, con diferentes manifestaciones, a todos los dominios de nuestro planeta. Sus efectos empezaron a mostrarse en el

\footnotetext{
* Departamento de Geografía, Universidad Nacional de Educación a Distancia (iprietoj@ hotmail.com).

** Departamento de Geografía, Universidad Autónoma de Madrid (concepción.fidalgo@ uam.es).

**** Departamento de Geografía, Universidad Autónoma de Madrid (juanantonio.gonza lez@uam.es).

${ }^{1}$ Este trabajo ha sido financiado con el proyecto CGL 2011-26781 (Ministerio de Ciencias e Innovación): Mineralogénesis, procesos geobiológicos y evolución ambiental en lagunas salinas del centro peninsular. Agradecidos. Los autores manifestamos además nuestro agradecimiento al personal de los Ayuntamientos de Fuentelespino de Haro, Villaescusa de Haro y Las Pedroñeras por todas las facilidades dadas en el curso de la investigación en sus respectivos Archivos Municipales. Nuestra gratitud también, por el mismo motivo, a la Directora del Archivo del Ministerio de Fomento.
} 
siglo XIV y su etapa final coincidió con las postrimerías del siglo XIX. En las latitudes medias, al frescor de sus ambientes (atestiguado por la frecuencia con la que se helaron numerosos ríos europeos y entre ellos también los españoles como, el Ebro, el Tajo y otros), hay que añadir unas estaciones que pasaron a conocer una anormal irregularidad al alternar largos periodos con años de extrema sequía con otros protagonizados por continuos temporales ${ }^{2}$. Acompañando a esta situación ambiental, se tienen numerosas noticias de cómo las regiones del interior, sobre todo las emplazadas en algunas cuencas fluviales de la Submeseta Sur, padecieron la existencia de extensas áreas palustres, cuyos efectos palúdicos revistieron una notable gravedad sobre la población. Así, son incontables los lugares peninsulares donde se jalonaron en el tiempo, y de modo especial a partir del último tercio del siglo XVIII, episodios de calenturas intermitentes, denominadas en la época «fiebres tercianas, cuartanas o calenturas pútridas» (García Ruipérez y Sánchez González, 1991; Capel, 1998-1999).

Todavía no se conoce con rigor si este auge desmesurado de las áreas encharcadas fue uno de los efectos derivados de las situaciones meteorológicas de la P.E.H. y vinculado a los prolongados temporales de agua, arriba aludidos; o si bien a este proceso de anegamiento habrían de sumarse las actuaciones del hombre en las vertientes y fondos de valle. Hoy nos inclinamos por una convergencia de fenómenos naturales y antrópicos para explicar la existencia de tantos humedales, variando el porcentaje de la responsabilidad natural y/o antrópica de unos parajes a otros (González, Fidalgo y Prieto, 2013).

\section{LOCALIZACIÓN DE LA ZONA DE ESTUDIO}

Independientemente de los motivos, naturales y/o antrópicos, que posibilitaron el desarrollo de las áreas pantanosas en las cuencas del interior peninsular, algunas de ellas conocieron frecuentes y extensos humedales que se alojaron de modo preferente en las hondonadas y vegas fluviales. Ello supuso un peligro para la salubridad y también una importante merma de la superficie agrícola en suelos aluviales que, con abundante materia orgánica, eran los más fértiles y apropiados para los cultivos. Entre las cuencas de la Submeseta Sur que se inundaron con frecuencia destacan las pertenecientes a la red hidrográfica del Alto Guadiana. Éstas ofrecen como elementos propiciatorios:

\footnotetext{
${ }^{2}$ Estos eventos, identificados por las innumerables rogativas «pro pluvia» o «pro serenitatem», fueron uno de los principales responsables de las reiteradas hambrunas que se conocieron en Europa occidental durante esta etapa histórica.
} 
- Lechos con mínimas pendientes y, por ello, propensos desde hacía muchos siglos a la génesis de tablazos;

- Caudales muy reducidos incapaces de realizar importantes acciones erosivas pero, por el contrario, muy proclives, debido a la baja velocidad de sus aguas, a los procesos de sedimentación de arenas, limos y arcillas;

- Pulsaciones de corriente o riadas de reducido volumen y con cortos períodos de retorno, incapaces de abrirse paso y desbrozar las áreas encharcadas;

- Aprovechamientos hidráulicos (molinos y batanes) funcionales, al menos desde el siglo XVI, mal emplazados y dotados de unas infraestructuras (caces, balsas, etc.) que alteraron la dinámica fluvial al desviar las corrientes de agua en numerosos tramos de los valles y represar ocasionalmente sus flujos.

Todas estas circunstancias se dieron en la cuenca del río Záncara (figura 1), objeto de nuestro estudio, donde, además, hay un hecho que llama poderosamente la atención en este valle: el distante emplazamiento que casi todas las localidades ofrecen con respecto a su cauce. Exceptuándose a Huerta de la Obispalía y a Zafra de Záncara (alzada en la cima de una sierrecilla), ninguna otra localidad se decidió a disponerse en las inmediaciones de su vega. Tan sólo, El Provencio se aventuró a ocupar tal posición con el fin de beneficiarse del trazado del antiguo camino de Madrid a Albacete. No obstante, este aparente privilegio fue motivo del elevado coste de vidas que, a lo largo de la época moderna y contemporánea, sufrió su población, debido a los frecuentes episodios de fiebres tercianas que los encharcamientos inmediatos del Záncara desencadenaban con fatal frecuencia. Como caso a considerar, en el otro extremo, apuntar cómo la localidad de La Alberca de Záncara, a pesar de su hidro-topónimo, se ubicó a una considerable distancia $(8 \mathrm{~km})$ del río. Parece más que probable que razones de salubridad justificasen, en sus orígenes, el alejado emplazamiento de las diversas localidades de su cuenca fluvial.

\section{El valle del Záncara: características y testigos de su pasado encharcado}

El río Záncara, principal afluente del Alto Guadiana, tiene su nacimiento en las estribaciones que bordean el flanco occidental de la Serranía de Cuenca. Su cauce, con $220 \mathrm{~km}$ de longitud (División Hidrológica de Ciudad Real, 1883), discurre por un valle donde, antes de alcanzar la planicie manchega, conoce una sucesión de trechos encajados y con cierta pendiente junto a otros de confines más amplios y de mínima inclinación. Aquellos se labran sobre las 
estructuras plegadas que constituyen el abanico de alineaciones mesozoicas de la Sierra de Altomira y los segundos se han modelado sobre afloramientos cenozoicos de rocas lábiles -margas, arcillas, yesos- (Prieto, 2009).

Al igual que otros afluentes del Alto Guadiana, el Záncara ofrece unos caudales escasos y de contrastada irregularidad típicos de un régimen pluvial mediterráneo.

FIGURA 1

\section{LOCALIZACIÓN DE LA CUENCA DEL RÍO ZÁNCARA Y DE LAS PRINCIPALES ÁREAS QUE FUERON OBJETO DE PALERÍAS}

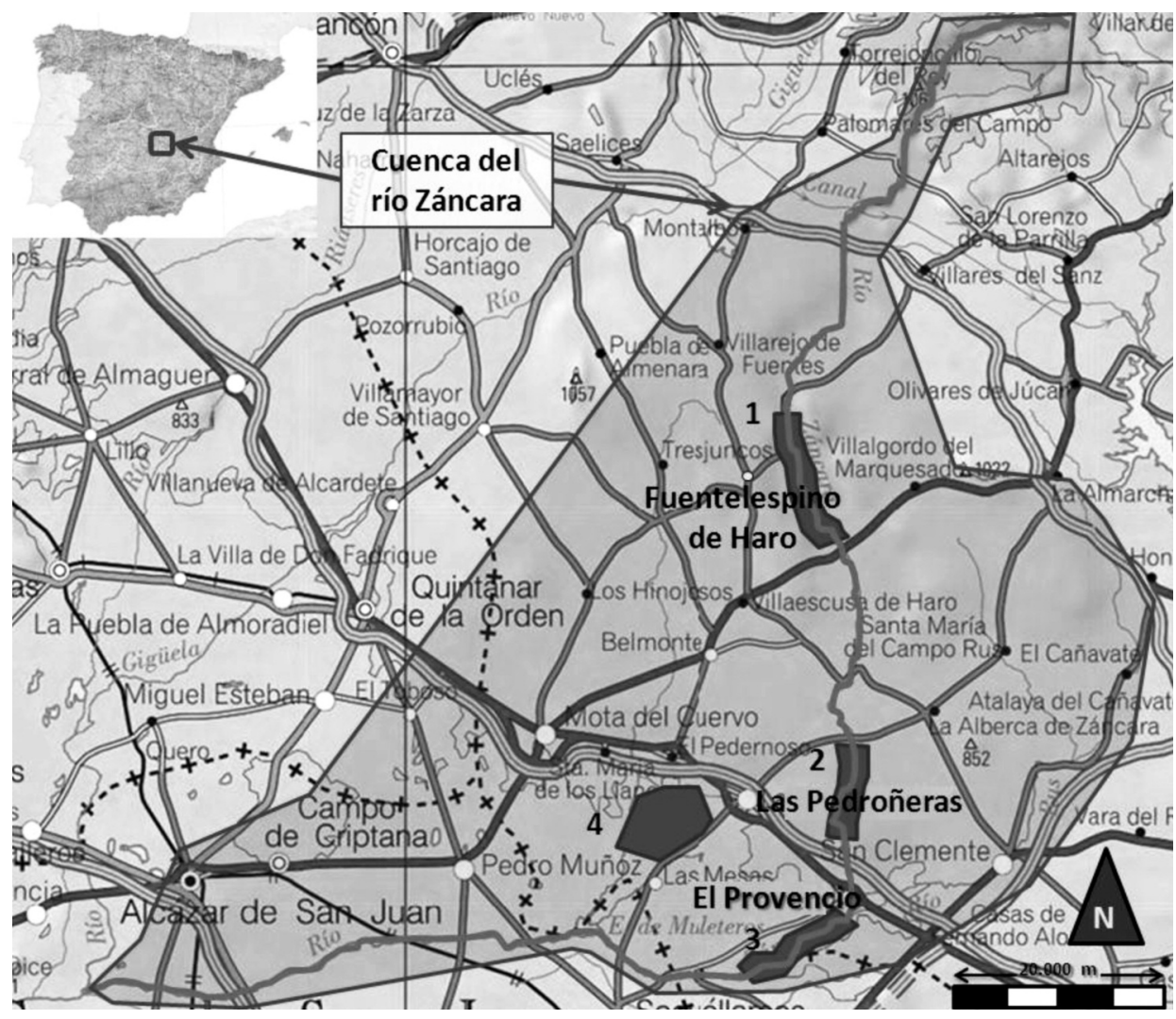

Nota: 1, 2 y 3) Valle del Záncara en las inmediaciones de las localidades de Fuentelespino de Haro (incluyendo los Arroyos del Cazarejo y las acequias de Santa Bárbara), Las Pedroñeras y El Provencio respectivamente; 4) Área de la Acequia mayor, de las Huertas y Acequia del Roble en Las Pedroñeras.

Fuente: elaboración propia.

Estudios Geográficos, Vol. LXXV, 277, pp. 553-573, julio-diciembre 2014

ISSN: 0014-1496, eISSN: 1988-8546, doi: 10.3989/estgeogr.201417 
Los motivos que determinaron la tendencia a la aparición de áreas pantanosas en su fondo de valle radican, en varias circunstancias, como ya se ha mencionado: la escasa inclinación del perfil longitudinal del río, sobre todo en su tramo final o manchego; la relativa frecuencia de intensas precipitaciones en su cuenca; y unos usos del suelo que eliminaron, desde tiempos muy tempranos, la fitoestabilización de las vertientes permitiendo la ingente llegada de sedimentos detríticos desde el dominio de las laderas hasta su llanura de inundación, reduciendo la pendiente y favoreciendo los procesos de encharcamiento.

Además, la acción del hombre en las vegas propició el remanso de las aguas. Fundamentalmente, aquella estuvo asociada a la presencia de una elevada cantidad de artilugios hidráulicos (molinos y batanes) que, entre Zafra de Záncara y la desembocadura, sobrepasaron el número de 30. El inicio de su funcionamiento fue anterior al siglo Xvi pues aparecen mencionados en las Relaciones Topográficas de Felipe II (Prieto y Gutiérrez, 2009) y su cese tuvo lugar en las postrimerías del XIX y primera mitad del Xx. En su emplazamiento prevalecieron los factores de accesibilidad y proximidad a los núcleos de población sobre los de aprovechamiento de las aguas. Así lo atestigua el que muchos de ellos se dispusieron en los tramos de menor pendiente, en amplias vaguadas y depresiones que, casi siempre, estaban encharcadas. Se despreciaron, pues, los trechos encajados, emplazados en los corredores abiertos por el río en los relieves cretácicos, peor comunicados, caracterizados por una pendiente del lecho algo más elevada y, por tanto, con unos flujos más veloces y más aptos para el aprovechamiento hidráulico de los artefactos.

Los trabajos de saneamiento en las vegas del valle del río Záncara son muy antiguos y, en un primer momento, debieron estar orientados al encauzamiento para mejorar el aprovechamiento de algunos artilugios hidráulicos, molinos invernizos, como relatan, en el siglo xvI, las Relaciones Topográficas de Socuéllamos (Arroyo Ilera, 1998), en la provincia de Ciudad Real. Éstas también mencionan, para Las Pedroñeras (Cuenca), la existencia de algunos parajes insanos. Por aquel tiempo, y sobre todo, en época posterior una vez confirmada la nefasta relación para el hombre entre las áreas pantanosas y las fiebres tercianas, los trabajos de drenaje orientados al saneamiento de terrenos debieron ser una labor relativamente cotidiana en muchos lugares como testifican las fuentes documentales estudiadas.

En la actualidad, raro es el sector fluvial, y sobre todo el que discurre por la planicie manchega, donde puedan examinarse las características originales que presentaba el primitivo Záncara. Por ello, todos los parámetros fluviales 
(anchura, profundidad, radio hidráulico, etc.) de su lecho coinciden aproximadamente con los trazados y las dimensiones artificiales que el hombre, secularmente, excavó en este fondo de valle para impedir el encharcamiento de la vega, siendo su cauce (y el de algunos afluentes) desbrozado o 'mondado'. También fueron retocadas y/o rectificadas sus pretéritas sinuosidades que, a modo de pequeños meandros, jalonaban su curso. Incluso, en ciertos tramos (como los localizados a la altura de Fuentelespino de Haro y aguas abajo de El Provencio), el desagüe de las zonas encharcadas exigió un nuevo trazado artificial; éste debía separarse de modo notorio del antiguo lecho para lograr disminuir su longitud y, con ello, aumentar la pendiente, pues caso de reparar sólo el cauce original no se habría obtenido ninguna ventaja para la desecación, siendo evidentes los riesgos de que las aguas se remansaran en poco tiempo ${ }^{3}$. El reconocimiento geomorfológico del valle y la existencia de numerosas fuentes documentales atestiguan el carácter empantanado ofrecido por su vega durante buena parte de las últimas centurias.

El análisis geomorfológico revela la existencia de un encharcamiento generalizado desde aguas arriba de Fuentelespino de Haro hasta la propia desembocadura. Pero los ámbitos que estuvieron plagados de continuos humedales coinciden con el tramo manchego de este río, es decir los caracterizados por una menor pendiente fluvial. En efecto, tras contornear el conjunto de relieves cretácicos, pertenecientes a las distintas estribaciones de la sierra de Altomira, el río Záncara se interna por las planicies y terrenos geológicos propiamente manchegos, por los que discurre durante bastantes decenas de kilómetros hasta alcanzar su confluencia con el Guadiana. Poco a poco, las vertientes que alojan su vega se disipan y, a partir del castillo de Santiago de la Torre, sus contornos son enmascarados por la amplia llanura manchega. Atestigua esta disipación morfológica la circunstancia de que su cauce fluye a 700$695 \mathrm{~m}$, mientras que las alturas más elevadas sólo se alzan unos veinte metros sobre aquel (Vértice Geodésico «El Provencio»: $721 \mathrm{~m}$ ). Más allá de este paraje, llanura y valle se confunden totalmente y la continuidad de los antiguos aguazales apenas se ve interrumpida a todo lo largo del valle, haciéndose especialmente notoria en el pantano de «los Muleteros».

La existencia de estos pretéritos ambientes encharcados se detecta a partir de las inmensas superficies cubiertas por suelos hidromorfos con sus típicas

\footnotetext{
${ }^{3}$ Todas estas actuaciones quedaron descritas en numerosos «expedientes de palerías» destinadas a sanear su vega y que se localizan en ciertos archivos municipales del valle. De igual modo están reflejadas en algunas memorias de los proyectos de desecación y saneamiento de terrenos que se conservan en el Archivo del Ministerio de Fomento.
} 
tonalidades grises y/o negruzcas, derivadas de un alto contenido en materia orgánica. Además, los cortes visibles, abiertos en las orillas del cauce, permiten advertir cómo en el seno de la materia orgánica se entremezclan diversos restos cerámicos, de los últimos siglos, atestiguando la reciente cronología de los encharcamientos.

También el análisis de las fuentes documentales ha detectado numerosas noticias sobre la existencia de múltiples aguazales en la vega. Entre ellas destacan por su interés: el Catastro de Ensenada, las descripciones efectuadas por distintos ingenieros, desde inicios del siglo XIX y, finalmente, los «Expedientes de Palerías», localizados en los Ayuntamientos de Fuentelespino de Haro y Las Pedroñeras, que serán objeto, a continuación, de un tratamiento específico.

Respecto al Catastro de Ensenada, el examen de sus Respuestas Generales y Particulares ha revelado cómo en aquel momento del siglo XVIII, numerosos parajes de algunos pueblos ubicados en el fondo del valle estaban cubiertos por las aguas. En efecto, lugares con topónimos identificados y situados con asiduidad en las inmediaciones del cauce permanecían como «incultos por desidia de sus propietarios» (Prieto et al., 2011) debido, entre otros factores, al frecuente encharcamiento de sus superficies; sin embargo, en tiempos anteriores fueron considerados muy productivos y fértiles. Así se desprende, también, de un expediente de palerías del 17/08/1789 del Archivo de las Pedroñeras, donde se describe que las «hazas» ubicadas en una hondonada se anegan por no tener corriente ni salida las aguas, debido a la inexistencia del adecuado desagüe de un arroyo que se alimentaba de una surgencia y de las precipitaciones caídas.

El encharcamiento del fondo del valle del Záncara continuó durante la siguiente centuria y fue analizado técnicamente por los ingenieros que, en distintas décadas, reconocieron los valles manchegos. Una de las aportaciones más antiguas fue efectuada a principios de aquel siglo por Agustín de Larramendi (1807). Sus apreciaciones, conformadas durante recorridos por las vegas, permitió calificarlas en «tan lastimoso estado» debido a que numerosos trechos del fondo de estos corredores fluviales estaban ocupados por unas aguas que se desparramaban por doquier y que por «descuido o indolencia de los ribereños se salía de madre e inundaba miles de fanegas de tierra». Además, aquellos aguazales propiciaban el desarrollo de las fiebres tercianas, responsables de una gran mortandad entre los habitantes de la comarca (Larramendi, 1807). Las causas del empantanamiento generalizado de toda la cuenca del Záncara fueron vinculadas a circunstancias naturales pero, sobre todo, a la intervención del hombre. A pesar del escaso caudal del río y la reducida pen- 
diente de la vega (calculada en unos 10-12 pies por legua) ${ }^{4}$, el valor de ambos parámetros era más que suficiente para que, sin obstáculos, los flujos fluviales circularan lentamente pero sin remansarse ni detenerse (Larramendi, 1807).

\section{PALERÍAS y PALEROS}

Sanear o avenar terrenos encharcados ha sido una labor que el hombre ha realizado desde tiempos inmemoriales y como prueba destaca la relación de labores dada con este fin por ciertos autores romanos. Entre ellos Columela, contemporáneo de Augusto y Tiberio, quien escribió que si el suelo fuese húmedo deberían abrirse desagües que facilitasen la eliminación del agua, señalando dos posibilidades: las zanjas abiertas en la superficie de los terrenos o los conductos subterráneos.

Los manuales de drenaje, escritos a finales del siglo xIx y principios del xx, distinguían entre «sanear» o «avenar» un territorio en función de la altura de la lámina de agua y del tipo de infraestructura que aquel nivel, más alto o más bajo, exigía para desaguarlo. De este modo, los lugares a sanear no solían contener excesivas aguas y para expulsarlas se cavaban zanjas o «canalizas descubiertas»; sin embargo, «avenar» consistía en hacer desaparecer las aguas en los parajes donde eran muy abundantes con el auxilio de tubos subterráneos. Para algunos autores, «avenar» $\mathrm{y}$ «drenar» eran sinónimos puesto que el desecamiento se lograba mediante la utilización de conductos colocados por debajo de tierra, siendo los ingleses los que habrían «inventado» este tipo de técnica agrícola (Larbalétrier, 1900).

Así pues sanear o avenar eran prácticas de "palería» efectuadas por unos trabajadores, más o menos expertos, denominados «paleros». El vocablo «palería» proviene del latín «palus» (laguna) (Diccionario de la Lengua Castellana de la Real Academia Española, 1992, pp. 1506) y consistiría en el «Arte u oficio de formar o limpiar las madres o hijuelas para desaguar las tierras bajas y húmedas». Curiosamente, en la vega del Záncara, la creencia popular relacionaba el nombre de los «paleros» con las pequeñas palas (figura 2) que, por norma general, utilizaban para movilizar los densos y pesados lodos en su trabajo cotidiano (Prieto, 2009). Semejante apreciación se tuvo, en el siglo XIX, en la ciudad de Albacete, donde unos obreros eran identificados como "paleros debido a que su oficio consistía en arrojar con palas el cieno» alojado en determinadas infraestructuras hidráulicas de desagüe (Morcillo, 2003, p. 183).

\footnotetext{
${ }^{4}$ Un «pie» medía aproximadamente 0,278 $\mathrm{m}$ y una «legua terrestre» 5,572 m.
} 


\section{FIGURA 2}

PALAS UTILIZADAS PARA EL SANEAMIENTO DE LA VEGA DEL ZÁNCARA EN FUENTELESPINO DE HARO

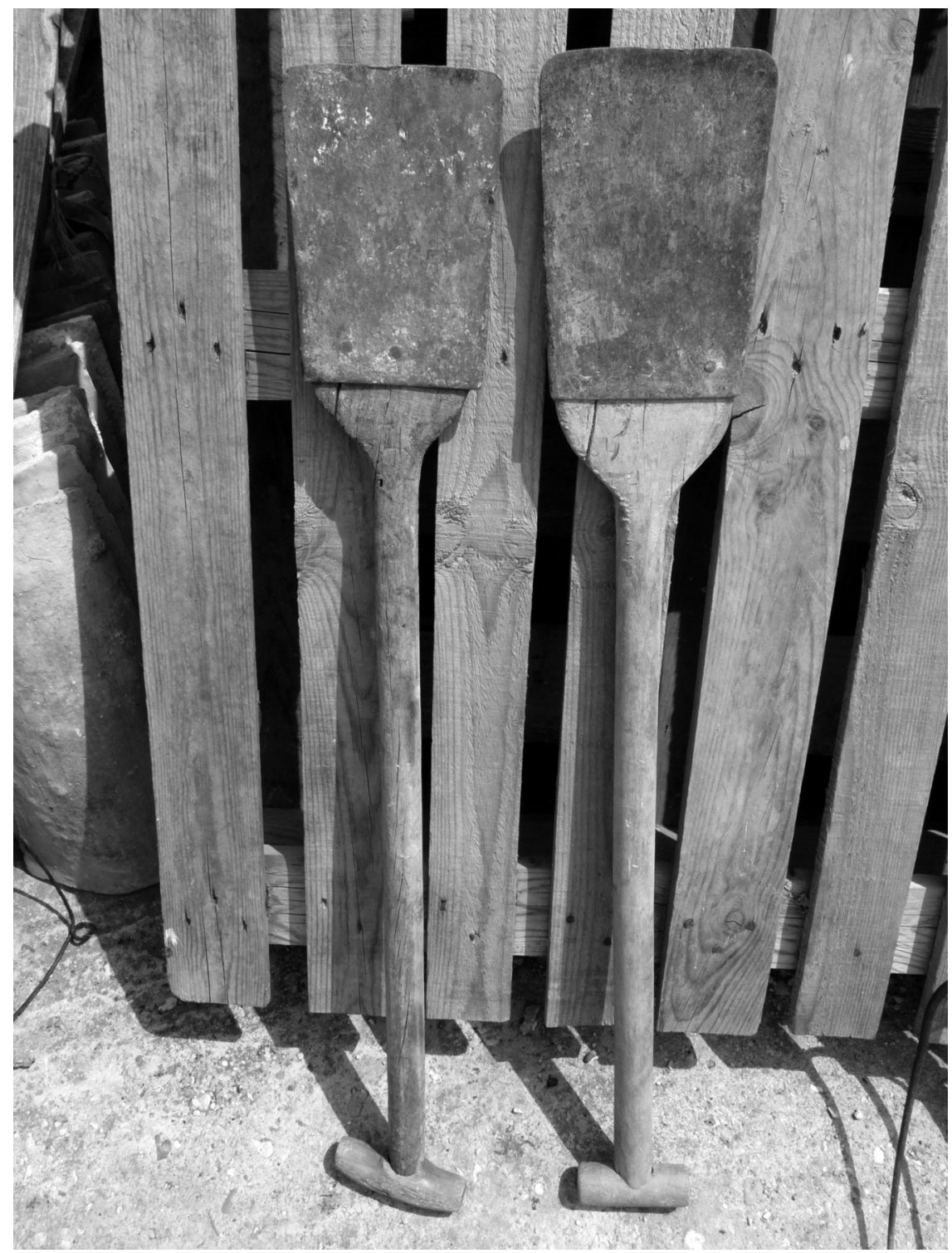

Fuente: los autores.

Estudios Geográficos, Vol. LXXV, 277, pp. 553-573, julio-diciembre 2014 ISSN: 0014-1496, eISSN: 1988-8546, doi: 10.3989/estgeogr.201417 
Los vocablos «palerías»y «paleros» fueron muy usados en algunas regiones españolas, mientras que en otras fueron prácticamente desconocidos. Así, el traductor al español de una obra francesa (Larbalétrier, 1900) de fines del siglo XIX -Miguel Menéndez y Soneta-, señaló, explícitamente, que dispuso, tanto en el título como en el subtítulo, las palabras «saneamiento de tierras de labor y drenaje», en detrimento de Manual de Palería ante "el riesgo de que muchas personas no supieran de qué trataba» la obra.

Los trabajos de palería ofrecían dos posibles modalidades según fuera su finalidad: saneamiento de los terrenos o limpieza del fondo de ríos/arroyos y canales de riego. Para esta última clase, los trabajos se iniciaban siempre por el tramo más alto o de aguas arriba removiendo el fondo con rastras y arrancando las densas comunidades higrófilas. Se aplicaban para ello palas y dragas de mano partiéndose desde el centro del cauce hacia las orillas y disponiendo los echadizos en la margen más alta del río o en la que tuviese pendiente hacia él para que escurriese sin encharcar las tierras colindantes. Una vez efectuada la limpia, se procuraba igualar el fondo con la rastra de dientes, evitando conformar cualquier tipo de socavones ni contrapendientes y apisonando las márgenes con la pala. En las infraestructuras de riego, esta operación era más compleja puesto que debía evitarse la deformación del fondo del cajero.

Cuando se trataba de trabajos de saneamiento con excavación de aguaderas se empezaba por la socavación de las «hijuelas» o «zanjas madres» en los puntos más bajos de los terrenos a desecar, perfilando después las líneas de drenaje, siguiendo una geometría normal a las hijuelas o en sentido radial.

Todavía a finales del siglo XIx (Diccionario Enciclopédico Hispano-Americano, 1887), estos trabajos se realizaban por un lado, con el fin de evitar las «emanaciones palúdicas» y por otro, aprovechar mejor el agua para el riego, utilizando en ocasiones los fangos fértiles que se obtenían a través de la limpieza.

\section{Las Palerías en España}

Los trabajos de palería se realizaron en diversas regiones peninsulares y con especial profusión en numerosas ocasiones. Existen datos que se remontan a las postrimerías de los tiempos medievales, en las cuencas fluviales de ciertos tributarios de la cuenca del río Ebro. Así, las actuaciones de «maestros paleros» $\mathrm{y}$ «endreçadores» o enderezadores de cauces, han sido estudiadas en los valles del Jiloca y del Huerva. Estas labores correctoras fueron llevadas a cabo por expertos locales y aportaron una abundante documentación, incluso 
de tipo notarial ${ }^{5}$. Consistieron en: la limpieza de cauces, canales y acequias y el rectificado de ciertos tramos meandriformes en los lechos de estos ríos, que discurrían «a bueltas», y eran propensos a la inundación de campos y pueblos (Rodrigo, 1997).

Noticias diseminadas de paleros pueden encontrarse también a finales del siglo XVI. Algunas coinciden con expertos de origen francés ${ }^{6}$ que efectuaron obras de palería en distintos ámbitos peninsulares y trabajando exclusivamente en las tareas de desecar terrenos, es decir haciendo zanjas o cavando los «cañales» de los pueblos para la evacuación de las aguas (Werner, 2001). De uno de ellos -Juan de Bayona- se sabe que efectuó labores de palería en valles de Soria, Burgos y La Mancha, sobre todo, por los alrededores de San Clemente (Cuenca) donde trabajó más de ocho años. Posteriormente, se estableció en Cuenca y, desde esta ciudad, su cuadrilla se dirigía al lugar donde se les ofrecía trabajo. Entre 1564 y 1569, llevó a cabo palerías en múltiples vegas de la actual Comunidad de Castilla-La Mancha (El Cañavate, Tragacete, Arcos de la Sierra, Ribatajada, Ribatajadilla, Torralba, Alconchel de la Estrella, El Peral, Casas Benitez, Carboneras, Belmonte, Monreal del Llano, Villanueva de la Jara, Iniesta y Verdelpino de Huete). Presencia de otros paleros, también oriundos de Francia, se tiene en diversas localidades de las proximidades del río Ebro como Miranda de Ebro, Navarrete, Salinillas de Buradón, Peralta, Briones, Fitero, Espronceda (Werner, 2001).

Referencias a pequeños contingentes de paleros, procedentes de algunas regiones europeas más húmedas, pueden detectarse de modo indirecto a partir de ciertas apreciaciones manifestadas por determinados autores del siglo XVII. Uno de ellos, Covarrubias en 1611, al abordar la voz «galochas», la vinculó a cierto tipo de calzado de madera, llamado así por los franceses especialmente los que habitaban en los Alpes y por los gascones «que vienen a España a hacer palerías». Utilizaban este calzado "porque andando en el agua, y en el cieno, abriendo las madres, y hijuelas, ningún otro calçado podrían traer que les fuere de provecho» (Covarrubias, 1611, p. 426).

En las vegas de algunos ríos de Castilla-La Mancha eran bien conocidas las prácticas de limpieza de ciertos cauces, aunque no eran denominadas palerías. Así lo sugieren las Ordenanzas de Riego de Argamasilla de Alba (Ciudad Real), de 1753, donde sus capítulos IX, X, XI y XII, al destacar las atribuciones

\footnotetext{
${ }^{5}$ Se localiza en el Archivo Municipal y Archivo de Protocolos Notariales de Daroca.

${ }^{6}$ Muchos de ellos se asentaron por algún tiempo o definitivamente en España lo que motivó que algunos de ellos tuviesen problemas con los tribunales de la Inquisición (Logroño, 15921593) debido a sus creencias no católicas (Werner, 2001).
} 
de un «Juez de Aguas» mencionan entre ellas la facultad de «ordenar la monda del río Guadiana» (Marín Magaz, 2007). Esta labor consistía en arrancar la vegetación higrófila que crecía en su lecho constituyendo un denso filtro vegetal que disminuía la velocidad del agua y, en ocasiones, favorecía su local empantanamiento. Estos trabajos se realizaban «desde antiguo» siendo costumbre obligada por el Concejo «hacer mondar a los vecinos que confinaran» con el lecho. Generalmente, estas faenas se efectuaban casi todos los años y se iniciaban a partir de principios de mayo, cuando las aguas comenzaban a descender; la duración de la monda se prolongaba durante dos semanas y en ciertos años se incrementaba hasta 3 ó 4 . Estas actuaciones se prosiguieron durante centurias y continuaron revistiendo un carácter anual, salvo en años muy lluviosos donde la vega se hallaba completamente cubierta por agua (Marín Magaz, 2007; Marín Magaz et al., 2008).

En los siglos XVIII y XIX, la mención a las palerías vuelve a aparecer de modo diseminado, aunque son algo más frecuentes en las tierras de Valencia, Alicante y Albacete. Así, por ejemplo, tres personas con profesión de «palero», figuraban entre los comisarios electores de Alicante de 1766-1770 (Rubio Fernández, 1988). También en la década de los años 1860, paleros, acostumbrados a este tipo de trabajos, oriundos de las huertas de Orihuela y Valencia, desbrozaron los cauces encenagados del Canal de María Cristina bloqueados por la falta de limpieza y ocasionando la aparición de abundantes áreas inundadas, perniciosas para la población de la ciudad de Albacete (Morcillo, 2003).

La palabra palería siguió utilizándose, cada vez con menor profusión a lo largo del siglo xx y, casi siempre, en localidades castellano-manchegas emplazadas cerca de vegas. Como puede apreciarse en:

- En las «Instrucciones» emanadas del reglamento de Policía Rural, Artículo. $3^{\circ}$, se señala que "compete al Servicio de Policía Rural [...] cuidar de que se conserven limpios los desagües de aguas corrientes y cuanto afecta a la limpieza, monda y palerías de los ríos y cauces, en el caso de que no existan en el término sindicatos de riegos o comunidades de regantes» (Gil García, 2005, p. 179).

- En la vega del río Trabaque (Cuenca), antes de la Guerra Civil, se hicieron palerías hasta el Estrecho de la Veguilla «necesarias y bien hechas con maquinas que da gusto verlas» (López Villaverde, 2004, p. 49).

- En algunos cauces y humedales manchegos, las «palerías» han sido asimiladas a diques realizados con máquina que ahondaban el cauce y recrecían las márgenes a ambos lados de los cauces con el fin de sanear terrenos (Sanz Donaire et al., 1994 y 1995). 


\section{Las Palerías en el valle del río Záncara}

En los Archivos Municipales de Fuentelespino de Haro y Las Pedroñeras se encuentran múltiples expedientes referentes a las obras de palerías realizadas en el río Záncara desde finales del siglo XviII hasta mediados del Xx. Incorporan, a su vez, diferentes documentos, que no siempre aparecen sistemáticamente, entre los que destacan:

- Petición al Gobernador Civil de la Provincia por parte de algún propietario o propietarios para que fuesen desecados y saneados los terrenos cercanos a cauces o arterias de riego.

- Escrito del Gobernador Civil informando al Ayuntamiento correspondiente de la admisión de la demanda y consentimiento para que la corporación municipal dispusiese los medios necesarios para que se acometan las labores de saneamiento.

- Elaboración de la relación de propietarios, o «terratenientes» que, al ser beneficiados por los trabajos, deberían pagar el costo de los trabajos. Este se establecía en proporción a la longitud del tramo a mejorar y que servía de «medianero» con la finca dispuesta en la otra margen del río o acequia. El Ayuntamiento se aseguraba el pago forzado imponiéndolo a todos los propietarios sin excepción ${ }^{7}$.

- Menciones relativas al precio de las obras. Los distintos precios establecidos permiten aproximarse a la idea del mayor o menor trabajo a realizar en función de que se tratara de un simple desbroce de la vegetación existente en el cauce o bien fuese también necesario excavar para profundizar su fondo, abrir nuevos desagües superficiales o rectificar localmente alguno trazado sinuoso.

- Pliego de Condiciones donde se aborda el plazo de ejecución, los jornales a cobrar por «técnicos» o «peones», el sistema de pago, el coste total de la obra, etc. Rara vez se matizan en ellos las exigencias que debían reunir los trabajos de palería que, casi siempre, se reducían al requerimiento de que las aguas fluyesen sin obstáculo que las remansara, o que las obras tuvieran «la profundidad y anchura que deba darse al cauce o acequia, apuntándose, todo lo más, que la monda se dará en el río a todo su ancho y toda la profundidad hasta llegar al firme». Sólo en contados

${ }^{7}$ El listado de terratenientes ofrece un notable interés porque permite advertir cómo la propiedad de la tierra estaba muy compartimentada en el fondo de la vega y cómo, además, las parcelas estaban dedicadas a cultivos, aunque no faltaban las de monte bajo, con escasa vegetación. 
expedientes, uno de 1800, al abordar las labores de «desbroce de malezas», se exige que alcancen «media bara en alto de las paredes de la acequia desde el lecho de las aguas con inclusión de dicho lecho, de forma que las citadas aguas queden sin impedimento alguno de su curso natural». En otro, de 1852, se declara que para que las obras estén bien hechas «han de tener profundidad en el centro del rio hasta dos palmos y medio, dejando de dos en dos estadales y en medio del mismo una varra que sirva de marcador para otra profundidad, y por los costados lo que naturalmente deba tener».

Como factor común, en todos los pliegos se establecía que las obras siempre tendrían un plazo para su finalización aunque, en ciertas ocasiones como en 1865, se especificaba una prórroga no superior a los 20 días. Algunos contemplan la posibilidad de que el plazo no pudiera cumplirse caso de que los trabajos «hubiera necesidad de suspenderlos por razón de lluvias y crecidas en el río». Desde el momento en que algún particular, o el propio ayuntamiento, establecía la necesidad de mondar y hacer palerías hasta la conclusión efectiva de los trabajos, solía discurrir un prolongado tiempo, buena parte del cual se perdía en la compleja tramitación de los expedientes. Sobre todo, en hacer llegar a los propietarios de las fincas colindantes la notificación y en que asumieran su aceptación; especialmente cuando aquellos habitaban en otras localidades más o menos vecinas. También, el proceso se dilataba a la hora de resolver los recursos presentados por algunos terratenientes, por el nombramiento de vocales de la «Junta de Palerías», por las labores de reconocimiento y tasación o por la diligencia de edictos en los sitios públicos de las localidades.

El saneamiento de las vegas debería iniciarse en las estaciones propicias cuando menos agua discurriese por los fondos. Así, en otros lugares de Castilla-La Mancha, como en el valle del Alto Guadiana, se efectuaba a partir de la primavera (Marín Magaz, 2007). Sin embargo, en Las Pedroñeras se realizaron fundamentalmente en: septiembre (Acequia Real, 1926); septiembre y octubre (Acequia Real, 1806); noviembre (río Záncara, 1866); noviembre-diciembre (La Acequilla, 1803); diciembre-enero (en la desecación del humedal de «lo de Andrés», 1803-1804) o en marzo (Acequia Real, 1865).

La necesidad continúa de ejecutar trabajos de palería en el río Záncara, así como en otras vegas manchegas, se derivaba de una serie de hechos naturales pero, sobre todo, de actuaciones antrópicas cuyos efectos se concatenaban secularmente a la hora de remansar los flujos de agua. En síntesis, los elementos que obstaculizaban su paso eran (Larramendi, 1807): 
- El elevado número de presas molinares que, aunque sus dimensiones no sobrepasaban «más de 5-6 pies de altura», eran suficientes para estancar las aguas en el fondo de valle a lo largo de más de «media legua» (unos $2.300 \mathrm{~m}$ aproximadamente), dada la escasa pendiente del cauce.

- La proliferación de infraestructuras caracterizadas por su bajo coste y pésima concepción, especialmente de los puentes que lejos de «dar paso libre a las aguas» se asemejaban a «malecones ejecutados para detener el río».

- Las características de las vegas encharcadas con una «extraordinaria propensión del terreno a criar plantas acuáticas» donde una espesa cubierta «de espadañas, eneas y broza entorpecía el curso de las aguas».

- Derivado del hecho anterior, los intereses de los ganaderos, también, fomentaron, siempre que pudieron, la desidia de remediar aquella penosa situación de la vega. Su estado anegado, a costa de terrenos perdidos a la agricultura, les permitió echar «sus muletadas, vacadas y toradas a las márgenes que producen bastante pasto, y las mantenían a poquísima o ninguna costa».

Los expedientes relativos a los trabajos de desagüe realizados en Fuentelespino de Haro datan del último tercio del siglo XIX y primera mitad del xx (1876, 1882, 1892, 1894, 1896, 1904, 1909, 1910, 1911 y 1918). Se localizaron siempre en la vega del río Záncara o en la de alguno de sus afluentes («Arroyo del Cazarejo» procedente de la localidad de Alconchel), así como en las acequias («Santa Bárbara y Moyano») que discurrían por el fondo de valle flanqueando, por una y otra margen, su lecho.

Por su parte, las palerías del término de Las Pedroñeras pertenecen, esencialmente, a los siglos XVIII y XIX y su documentación aporta mayor número de detalles. Se llevaron a cabo en diversos lugares de su término y fueron efectuadas, bajo subasta, casi siempre por paleros de la localidad o de otras muy próximas como El Provencio, Belmonte, Las Mesas y, en ciertas ocasiones, procedentes de Alicante y Murcia ${ }^{8}$. Entre los parajes saneados, además de los emplazados en la vega del Záncara (expedientes de 1852, 1857-58, 1860-61, 1865,1866 y 1871), destacan lugares relativamente alejados al valle situados al oeste del término municipal en un área endorreica donde dominan numerosos arroyuelos y lagunas. Se beneficiaban del aporte de aguas de dichos cauces reconvertidos en una red de infraestructuras de riego: «Acequia Mayor» (ex-

${ }^{8}$ Curiosamente el oficio de palero no parece reflejado en la documentación del Catastro de Ensenada de las localidades donde se llevaba a cabo estas actuaciones. 
pedientes de $1799,1800,1806,1865$ y 1926) y «secundarias» como la «Acequia de Las Huertas, Acequia del Roble» (1801, 1803 y 1865). Hoy todas estas acequias no son funcionales y han perdido, en su mayoría, el nombre como infraestructuras aunque algunas lo conservan en el mapa topográfico (Carrasco Sotos, 2003, Molina Carrión, 2001).

A destacar una de las actuaciones de palerías más antiguas de las que tenemos noticias en este valle, 17/08/1789, cuyo expediente se encuentra en los fondos documentales del Archivo de las Pedroñeras. Coincide con una petición de diferentes propietarios que poseían:

[...] hazas contiguas desde donde dicen el Puente de Campos hasta la Laguna llamada el Taray confinantes todas con la acequia, denominada del Monte raso [...] que se anegan por no tener corriente y la salida necesaria las aguas de un arroyo procedente de una surgencia y de las caídas por las precipitaciones [...] empantanan e inutilizan las dichas hazas y otras tierras de primera calidad que no solo producen los abundantes frutos que pueden y en otro tiempo han producido si [no] que estancadas las aguas infestan el aire y causan a la salud de los havitantes inmediatos los daños que tan patentemente se han experimentado de copiosas lluvias $[\ldots]$

Ante estas circunstancias aquellos terratenientes resolvieron:

[...] limpiar y profundar dicha hazequia en todo el distrito de nuestra pertenencia, concurriendo proporcionalmente, atendida la estensión de las respectivas hazas con la parte de gastos que se nezesitan para esta obra dirigiendo el cauze principal a la referida laguna del Taray, por la misma parte que claramente se manifiesta estubo hecho antes; dándole la capacidad y descenso necesario para el curso de las aguas $[\ldots]$

Otro expediente adjunto (20/10/1789) contiene un breve informe y descripción de las zonas anegadas e incorpora la petición de adelantar la mitad del dinero de lo que les pueda «corresponder por cada uno de los que tienen tierras confinantes con la azequia». Para conseguir este objetivo se establecía una relación de personas consideradas propietarios ${ }^{9}$ que más tarde, sería objeto de reticencia por algunos de ellos al ser incluidos en los costes de la limpieza. Finalmente, para confirmar la veracidad de esta petición, y como era costumbre entonces, fueron citados cuatro testigos expertos que eran agricultores de la localidad, coincidiendo todos ellos en los mismos hechos relativos a que:

\footnotetext{
${ }^{9}$ Posteriormente esta lista fue recusada por parte de algunas de las personas mencionadas como propietarios y por tanto obligadas a contribuir en los costes de la limpieza, argumentado no ser de su propiedad los terrenos sino de familiares.
} 
- Las aguas, procedentes de un arroyo de las lluvias, se empantanaban inutilizando las tierras;

- Todas las tierras anegadas eran de primera calidad en este término;

- Las aguas estancadas «maleficiaban»e «infestaban» el aire y causaban a la salud pública de los habitantes inmediatos daños como «los experimentados en los años anteriores coincidentes con copiosas lluvias, subsistiendo todavía parte de la epidemia que había sufrido el vecindario».

- El trazado de las obras seguiría el mismo curso que anteriormente tenían las distintas acequias y arroyos («cerrojos») que recorrían la zona.

Escasos años más tarde, otro documento en forma de «Ordenanzas del Real Consejo de Castilla», firmadas en la Villa de Las Pedroñeras el 18/09/1796 ${ }^{10}$, aborda un conjunto de medidas destinadas a la conservación de unas "palerías ya abiertas» y que coinciden con las descritas anteriormente y llevadas a cabo hacia 1789. Estas "prudentes ordenanzas» trataban de evitar «los excesos de los vecinos, pastores y demás transeúntes» que causaban el desperfecto en la «acequia principal, de las segundas, sus márgenes y sembrados». En un escrito posterior, firmado el 5 de noviembre de 1796, se vuelve a hacer alusión a la inexcusable necesidad de contar con la figura de un guarda celador, que sería pagado por los terratenientes, ya que «sin estos requisitos, todo es momentáneo y las acequias se hallaran ciegas a fines de la primabera inmediata».

En el siglo XIX, el mayor número de obras de palería se efectuó en el propio cauce del río Záncara y en algunos momentos, como ya se ha mencionado, con cierta asiduidad. La petición de saneamiento por parte de los propietarios colindantes con el río fue muy frecuente a lo largo de sus décadas. Estos tramos siempre aparecen limitados por distintos artilugios hidráulicos, hoy todos en ruinas o casi totalmente desaparecidos (Carrasco Sotos 2003, Prieto y González, 2009). Entre otros cabe mencionar los expedientes de 1800, 1803, 1806, 1852, 1857-1858 1865-1866, 1871 y 1926.

\section{CONSIDERACIONES FINALES}

Las condiciones de insalubridad en la vega del río Záncara se remontan, al menos y en ciertos tramos, a los inicios del siglo XVI y provocaron el despoblamiento de algunas pequeñas entidades o aldeas, como la de Záncara, por su carácter malsano (Relaciones Topográficas de Felipe II). Otras vegas fluviales,

${ }^{10}$ Archivo Municipal de Las Pedroñeras, Libro I, 1796. 
más o menos cercanas y pertenecientes a ciertos ríos del entorno de San Clemente (río Rus) o de la ciudad de Cuenca (río Moscas), debieron ser objeto de trabajos de saneamiento a mediados de aquella centuria, como lo refieren las noticias sobre trabajadores, procedentes de Francia, y dedicados a la desecación de áreas encharcadas.

El progreso de los ambientes empantanados en determinados trechos del Záncara y humedales próximos, alcanzó un notable máximo desde mediados del siglo XVIII, en algunas localidades ribereñas como lo sugieren diversas fuentes y esencialmente el Catastro de la Ensenada. Las causas que motivaron este auge de los dominios encharcados pueden ser vinculados a motivos climáticos, donde años con lluvias y temporales frecuentes ocasionarían la aparición y desarrollo de abundantes aguazales en el fondo de unas vegas con escasa pendiente. Sin embargo, las actuaciones humanas en las vertientes (prácticas de laboreo, ganado, incendios y aprovechamientos madereros o extinción de plagas de langosta, etc.), liberó ingentes cantidades de sedimentos hacia los fondos de valle. Su aporte no pudo ser allí retomado por unos cauces de escaso caudal y mínima velocidad de sus flujos a consecuencia de la bajísima pendiente del lecho, la presencia de numerosas presas molinares y unas infraestructuras, como los puentes, que lejos de permitir el paso franco de las aguas por sus ojos, las remansaban.

Para remediar esta situación, en la cuenca del Záncara y en otros ámbitos inmediatos, como el área endorreica de la Laguna del Taray, se efectuaron trabajos de palerías con cierta continuidad desde finales del siglo xviII destinados a: mondar cauces y acequias para darles la salida necesaria a sus aguas y evitar su posterior anegamiento o a desecar y sanear terrenos entonces ya encharcados.

El objetivo de estas labores atendió fundamentalmente a poner en cultivo o mejorar la productividad agrícola y a remediar los daños que las aguas estancadas causaban en la salud de los habitantes.

Estos trabajos de palerías produjeron una extensa, detallada y compleja documentación, generalmente depositada en algunos archivos municipales ${ }^{11}$. En ella, pueden abordarse diferentes objetivos geográficos e históricos al afrontarse no sólo aspectos del paisaje rural sino también de índole socio-económico (trámites a realizar en un trabajo de palería, nombre de los propietarios y datos de sus propiedades, precios de los jornales; coste de los trabajos por unidad de longitud (estadal); características de los pliegos de condiciones, etc.).

${ }^{11}$ Recientemente, hemos localizado expedientes de «palerías» en los Archivos Municipales de localidades emplazadas en las cuencas de otros ríos manchegos. 
A través de la documentación consultada hasta el momento, los paleros procedían generalmente de zonas del levante peninsular y anteriormente de fuera del territorio español; aunque en algunos casos se menciona que residían en la localidad.

Es necesario continuar ampliando la información a otros ámbitos cercanos, así como a otras vegas y áreas pantanosas de la Submeseta Sur, para tener un conocimiento riguroso de este tipo de intervenciones que debieron ser generales en todas ellas. Así se alcanzaría una imagen más precisa de cómo eran estos humedales en el pasado, qué procesos intervinieron en su génesis, natural (mayor humedad durante la P. E. H.) y antrópica, y un inventario de aquellos parajes donde han desaparecido totalmente.

Fecha de recepción: 15 de enero de 2013.

Fecha de aceptación: 30 de mayo de 2013.

\section{BIBLIOGRAFIA}

Arroyo Ilera, F. (1998): Agua, Paisaje y Sociedad en el siglo XVI, según las Relaciones Topográficas de Felipe II. Madrid, Ediciones del Umbral, 246 pp.

Capel, H. (1998-1999): "Medicina y clima en la España del siglo xviII". Revista de Geografia, 32-33, pp. 79-105.

Carrasco Sotos, A. (2003): Por campos de Las Pedroñeras. Rutas de una Geografía olvidada. Cuenca, A. Carrasco y A. D. I. El Záncara, 127 pp.

Covarrubias, S. (1611): Tesoro de la Lengua Castellana o Española. Madrid, Luis Sánchez Impresor, 78 pp.

División Hidrológica de Ciudad Real (1883): Itinerarios del río Guadiana y de todos sus afluentes. Madrid, Imprenta de Fortanet.

García Ruipérez, M. y Sánchez González, R. (1991): "La epidemia de tercianas de 1786 en la Antigua provincia de Toledo". Asclepio, 43, pp. 267-300.

Gil García, P. (2005): Las hermandades sindicales de labradores y ganaderos (1944-1977). Cuenca, Ediciones Universidad de Castilla-La Mancha, 201 pp. Colección "Almud".

González Martín. J. A.; Fidalgo Hijano, C y Prieto Jiménez, I. (2013): "La Pequeña Edad del Hielo en la Península Ibérica: Estado de la cuestión”, en: La Corte de los Borbones: la crisis del sistema cortesano, vol. I. Madrid, Polifemo, pp. 237-282.

Larbalétrier, A. (2008): Manual práctico de saneamiento de las tierras de labor. Pequeña Enciclopedia de Agricultura. (1900). Valladolid, Editorial Maxtor, 164 pp.

Larramendi, J. A. (1858): Informe sobre la necesidad de desaguar las lagunas de La Mancha. (1807). Madrid, Imprenta de José C. de la Peña, 82 pp.

López Villaverde, A. L. (2004): Honra, Agua y Pan: un sueño comunista de Cipriano López Crespo (1934-1938). Cuenca, Servicio de Publicaciones de Castilla-La Mancha, 120 pp. 
Marín Magaz, J. C. (2007): El Hombre y el agua de las Lagunas de Ruidera (Usos históricos, siglos XVI a mediados del XX). Tomelloso, Ediciones Soubriet, 386 pp.

Marín Magaz, J. C.; Fidalgo Hijano, C. y González Martín, J. A. (2008): "Los Padrones de riego de Argamasilla de Alba (Ciudad Real): un documento paracatastral regulando los derechos al agua en los siglos XVIII y XIX". CT Catastro, pp. 181- 201.

Molina Carrión, F. (2001): Historia de Las Pedroñeras. Más de 500 años de la vida de una antigua villa de la Corona de Castilla. Cuenca, Concejalía de Cultura y Diputación Provincial de Cuenca, 358 pp.

Morcillo, M. (2003): "Cuerpos de seguridad municipal en Albacete durante el siglo XIX: Los guardas del Canal de María Cristina”. Ensayos, Revista de la Facultad de Educación de Albacete, 18, pp. 175-184.

Prieto Jiménez, I. (2009): La vega conquense del Záncara. Sus aguas y la actividad de sus molinos harineros. Cuenca, Edit. Alfonsípolis, 208 pp.

Prieto Jiménez, I. y González Martin, J. A. (2009): "Molinos y Batanes: Condiciones medioambientales en sus parajes de emplazamiento", en: Actas V Congreso Internacional de Molinologia. Alcázar de San Juan, 2005. Toledo, Junta de Comunidades de Castilla-La Mancha, pp. 553-562.

Prieto Jiménez, I. y Gutiérrez Romero, B. (2009): "Evolución histórica de los molinos del río Záncara. De las Relaciones Topográficas a la actualidad”, en: Actas V Congreso Internacional de Molinología. Alcázar de San Juan, 2005. Toledo, Junta de Comunidades de Castilla-La Mancha, pp. 93-105.

Prieto Jiménez, I.; Fidalgo Hijano, C.; González Martin, J. A. y Prieto Valencia, B. (2011): Fuente el Espino de Haro en los siglos XVII y XVIII. Cuenca, Editorial Alfonsípolis, $224 \mathrm{pp}$.

Rodrigo Estevan, M. ${ }^{a}$ L. (1997): "Maestros paleros y "endreçadores" de ríos. Notas sobre la construcción del paisaje a fines del siglo XV en la Cuenca del Jiloca y del Huerva". Xiloca, 20, pp. 49-76.

Rubio Fernández, M. D. (1988): "Diputados del Común y Síndicos Personeros en Alicante: 1766-1770". Revista de Historia Moderna, 6-7, pp. 87-102.

Sanz Donaire, J. J. (1995): "De humedales a secarrales: ¿inexorable evolución de las hidrocoras del centro peninsular?". Anales de Geografía de la Universidad Complutense, 15, pp. 663-671.

Sanz Donaire, J. J.; Díaz Álvarez, M. D. y Sánchez Pérez de Évora, A. (1994): "La Mancha: Transformaciones forzadas de los humedales". Boletín A.G.E., 18, pp. 39-61.

Varios (1887): Diccionario Enciclopédico Hispano-Americano de Literatura, Ciencias y Artes. Bacelona, Ed. Montaner y Simón.

Varios (1992): Diccionario de la lengua castellana compuesto por la Real Academia Española. Madrid, RAE.

Werner, T. (2001): Los Protestantes y la Inquisición en España en tiempos de Reforma y Contrarreforma. Belgium, Leuven University Press, 717 pp. 


\section{RESUMEN}

Las últimas centurias de la Pequeña Edad del Hielo (1700-1900) se manifestaron con una enorme progresión de las áreas encharcadas en las cuencas fluviales y endorreicas del centro peninsular. Este incremento de los aguazales parece tener su origen en una combinación de factores naturales y actuaciones antrópicas. Los primeros vinculados a una gran irregularidad anual de las precipitaciones donde alternaron años muy secos con otros de notable humedad. Las segundas asociadas a los usos que el hombre de aquella época hizo del suelo y de las aguas. Con el fin de paliar esta situación fueron necesarias innumerables obras de 'monda' en los cauces y acequias de riego o molinares. Estos trabajos, así como los de desecación de humedales, fueron realizados por los paleros, una antigua profesión que cobró notoria importancia en algunas cuencas fluviales manchegas, como la del río Záncara, durante las centurias del XVIII y del XIX.

PAlabras Clave: humedales; encharcamiento; paleros; desecación; Pequeña Edad del Hielo.

\section{AbSTRACT}

The last centuries of the Little Ice Age (1700-1900) led to a huge advance of flooded areas in the fluvial and endorheic basins of the Spanish peninsular center. This increase in the area of marshland appears to have had its origin in a combination of natural processes and anthropogenic activities. The former are related to considerable irregularities in annual rainfall as very dry years alternated with others of great humidity. The latterhave to do with human usage of soil and water. As a means of mitigating the general situation, countless works were undertaken to clear river beds and irrigation and mill ditches. These works, as well as the drying of wetlands, were carried out by wetland drainers known as paleros, an ancient profession which became remarkably important in some river basins of the region of La Mancha, such as the Záncara River, during the eighteenth and nineteenth centuries.

KEY WORDS: wetlands; ponding; drainers; drying activities; Little Ice Age.

\section{RÉSUMÉ}

Les derniers siècles du petit âge glaciaire (1700-1900) se sont manifestés par une progression énorme des zones inondées dans les bassins fluviaux et endoréiques du centre de la péninsule Ibérique. Cette augmentation des marécages semble provenir d'une combinaison de facteurs naturels et d'actions anthropiques. Les premiers sont liés à une grande irrégularité des précipitations annuelles, avec alternance d'années très sèches et d'autres remarquablement humides. Les deuxièmes sont liées à l'usage fait du sol et des eaux par l'homme à cette époque. D'innombrables travaux ont été nécessaires pour débarrasser les ruisseaux et les rigoles et remédier cette situation d'eaux stagnantes. Ces travaux, ainsi que le tarissement de zones humides, ont été faits par les « paleros» (draineurs), un ancien métier qui avait acquis une importance remarquable dans certains bassins fluviaux de La Mancha, comme celui du Záncara, pendant le XVIIIe et le XIXe siècles.

MoTS CLÉs: zones humides; marécages; paleros; tarissement; Petit Âge Glaciaire. 